\title{
Radiative forcing due to aviation water vapour emissions
}

Article

Accepted Version

This is the author's postscript of the published version

Wilcox, L.J., Shine, K.P. and Hoskins, B.J. (2012) Radiative forcing due to aviation water vapour emissions. Atmospheric Environment, 63. pp. 1-13. ISSN 1352-2310 doi:

https://doi.org/10.1016/j.atmosenv.2012.08.072 Available at https://centaur.reading.ac.uk/29029/

It is advisable to refer to the publisher's version if you intend to cite from the work. See Guidance on citing.

Published version at: http://www.sciencedirect.com/science/article/pii/S135223101200859X

To link to this article DOI: http://dx.doi.org/10.1016/j.atmosenv.2012.08.072

Publisher: Elsevier

All outputs in CentAUR are protected by Intellectual Property Rights law, including copyright law. Copyright and IPR is retained by the creators or other copyright holders. Terms and conditions for use of this material are defined in the End User Agreement.

\section{www.reading.ac.uk/centaur}

\section{CentAUR}

Central Archive at the University of Reading

Reading's research outputs online 


\title{
Radiative forcing due to aviation water vapour emissions
}

\author{
L. J. Wilcox, K. P. Shine, and B. J. Hoskins \\ Department of Meteorology, University of Reading, Earley Gate, P.O. Box \\ 243, Reading, RG6 6BB, UK.
}

\begin{abstract}
Three emissions inventories have been used with a fully Lagrangian trajectory model to calculate the stratospheric accumulation of water vapour emissions from aircraft, and the resulting radiative forcing. The annual and global-mean radiative forcing due to present-day aviation water vapour emissions has been found to be $0.9[0.3$ to 1.4$] \mathrm{mW} \mathrm{m}^{-2}$. This is around a factor of three smaller than the value given in recent assessments, and the upper bound is much lower than a recently suggested $20 \mathrm{~mW} \mathrm{~m}{ }^{-2}$ upper bound. This forcing is sensitive to the vertical distribution of emissions, and, to a lesser extent, interannual variability in meteorology. Large differences in the vertical distribution of emissions within the inventories have been identified, which result in the choice of inventory being the largest source of differences in the calculation of the radiative forcing due to the emissions.

Analysis of Northern Hemisphere trajectories demonstrates that the assumption of an e-folding time is not always appropriate for stratospheric emissions. A linear model is more representative for emissions that enter the stratosphere far above the tropopause.
\end{abstract}

\section{Introduction}

2 The radiative forcing due to aviation water vapour emissions has often been assumed to be negligible (e.g. Sausen et al. (2005)), and their climate impact has not recently been reported in detail. However, a recent European assessment (Lee et al. (2010); see also Lee et al. (2009)) of the climate impact of aviation indicated a very large uncertainty in this forcing, with a best estimate of 2.8 $\mathrm{mW} \mathrm{m}^{-2}$ and an upper limit of the $90 \%$ likelihood range reaching $20 \mathrm{~mW} \mathrm{~m}^{-2}$ for the 2005 radiative forcing. This would exceed the best-estimate forcing due to oxides of nitrogen and linear contrails, and indeed would be comparable to the best estimate for aviation $\mathrm{CO}_{2}$ radiative forcing $\left(28 \mathrm{~mW} \mathrm{~m}^{-2}\right)$. Hence, it is important to investigate whether the reported "best estimate" is robust, and whether the reported likelihood range is justified. 
Many studies investigating the climate impact of water vapour emissions focus on hypothetical fleets of either supersonic or liquid hydrogen fuelled aircraft, or forecast subsonic fleets (e.g. Gauss et al. (2003), Morris et al. (2003), Ponater et al. (2006)). There are few published estimates of the climate impact of water vapour emissions calculated using present-day global emissions from aviation, and none that are based on a high-resolution representation of the atmospheric circulation.

Both horizontal and vertical resolution have been shown to be important when calculating stratosphere to troposphere exchange (e.g. Kentarchos et al. (2000); Land et al. (2002)), which is likely to be an issue when evaluating the climate impact of water vapour emissions. Only stratospheric emissions of water vapour by aviation are likely to significantly perturb the background humidity, and hence have a radiative effect, because of their persistence and the low ambient humidity there.

In this paper a number of aviation emission inventories will be compared, and the sensitivity of the mass of water vapour emissions deposited directly into the stratosphere to meteorology and inventory choice will be discussed. A fully Lagrangian trajectory model will be used to find the perturbation to the natural background humidity resulting from water vapour emissions using the different inventories. New estimates of the residence time of water vapour emissions in the stratosphere are also presented alongside an analysis of the validity of the commonly used e-folding lifetime. Residence times presented here are calculated directly from the perturbation concentrations, avoiding the need for assumptions about the nature of the decay of the aviation-induced perturbations with time. The radiative forcing due to the perturbation in water vapour amounts due to aviation emissions is then presented, and the sources of uncertainty discussed.

\section{Data sets}

Meteorological data are primarily taken from the European Centre for Mediumrange Weather Forecasts (ECMWF) reanalysis ERA-Interim (Dee et al., 2011). ERA-Interim extends from 1979 to the present, and has been used on model levels with a resolution of T255 L60 to calculate trajectories. Gridded data on 37 isobaric surfaces, and on the $|\mathrm{PV}|=2 \mathrm{PVU}\left(1 \mathrm{PVU}=1 \times 10^{6} \mathrm{~K} \mathrm{~m}^{2} \mathrm{~kg}^{-1}\right.$ $\mathrm{s}^{-1}$ ) surface, with a horizontal resolution of $\sim 0.703^{\circ} \times 0.703^{\circ}$ has been used to identify the tropopause. Liu et al. (2010) highlight problems with over dispersion in vertical transport when trajectories are calculated based on ERA-40 data, showing ERA-Interim to be clearly superior for the present purposes.

Some ERA-Operational data are also used to test the sensitivity of the result to the choice of meteorological data set. Where these data are used it is on model levels with a resolution of T159 L60, and on 23 isobaric levels with a horizontal resolution of $\sim 1.125^{\circ} \times 1.125^{\circ}$.

Aviation water vapour emissions are taken from three inventories: Aviation Environment Design Tool (AEDT) (Kim et al., 2005) for 2006, AERO2k (Eyers et al., 2004) for 2002, and QUANTIFY (Owen et al., 2010) for 2000. The 


\begin{tabular}{|c|c|c|c|}
\hline Inventory & $\begin{array}{c}\text { Annual total } \\
\text { emissions (Tg) }\end{array}$ & $\begin{array}{c}\text { Total emissions } \\
\text { above } 9 \mathrm{~km}(\mathrm{Tg})\end{array}$ & $\begin{array}{c}\text { \% emissions } \\
\text { above } 9 \mathrm{~km}\end{array}$ \\
\hline AEDT & 233 & 155 & 67 \\
AERO2k & 191 & 94 & 49 \\
QUANTIFY & 266 & 204 & 77 \\
\hline
\end{tabular}

Table 1: Global- and annual-total emissions of water vapour (Tg) from AEDT (2006), AERO2k (2002) and QUANTIFY (2000), total emissions above $9 \mathrm{~km}$ $(\mathrm{Tg})$, and the percentage of total emissions above $9 \mathrm{~km}$.

fact that the inventories are for different years limits the possibilities for direct comparison, although the differences are not expected to be large between years that are so close together. The analysis presented in this paper primarily focuses on the more recent AEDT inventory. Both AEDT and AERO2k can predict fuel burn with an average error of $<5 \%$ compared to operational values when aircraft movements are known (Malwitz et al. (2005); Eyers et al. (2004)). AEDT and AERO2k both incorporate 4D movement data over the US and western Europe, and rely on schedule data for the rest of the world (Kim et al. (2005); Eyers et al. (2004)). However, AERO2k is based on only six weeks of 4D data, and six days of schedule data, with monthly data calculated based on annual trends in Official Airline Guide schedules (Eyers et al., 2004). AEDT incorporates as much real data as possible, and uses a much more extensive database of aircraft performance parameters (Kim et al., 2005). Hence, it is believed to be most accurate.

\subsection{Vertical distribution of emissions}

The residence time of water vapour emissions in the stratosphere has been shown in previous studies to be sensitive to the height of the emissions above the tropopause (e.g. Gettelman (1998)). Hence, the effect of differences in the vertical distribution of water vapour emissions between inventories needs to be investigated. The global-mean vertical distribution of annual-total water vapour emissions in AERO2k, QUANTIFY and AEDT are shown in Figure 1. Table 1 shows the total mass of emissions, and the mass of emissions above $9 \mathrm{~km}$, in each inventory.

The maximum emissions, and the largest differences between the vertical profiles from the three inventories, are found at cruise altitudes between 9 and $12 \mathrm{~km}$. Typical tropopause altitudes in the extratropics and polar latitudes tend to lie within, or just below, this altitude range. The impact of these differences on the accumulation of water vapour, and its radiative forcing, are quantified in Sections 5 and 6.

In AEDT, the largest emissions are found at altitudes between 10 and 12 $\mathrm{km}$, while in AERO2k and QUANTIFY they are concentrated in a narrower range from 10 to $11 \mathrm{~km}$. This results in a greater proportion of AEDT emis- 


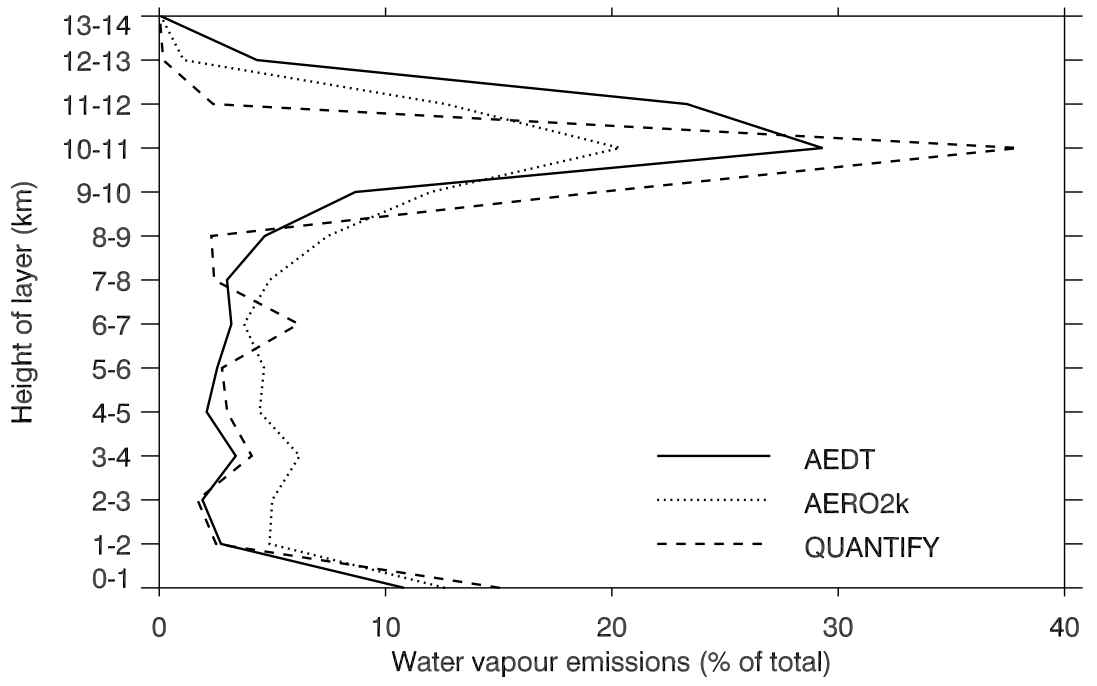

Figure 1: Global- and annual-mean altitude distribution of total water vapour emissions due to aviation, as a percentage of the total, from AEDT (2006), AERO2k (2002) and QUANTIFY (2000).

sions entering the atmosphere at high altitudes where they are more likely to accumulate, compared to AERO2k and QUANTIFY emissions (see Table 1). This difference is likely to be the result of variations in input data, and the use of specified cruise altitudes in AERO2k and QUANTIFY compared to a probability distribution about typical cruise altitudes in AEDT.

Water vapour emissions are much more evenly distributed with altitude in AERO2k compared to AEDT and QUANTIFY. A similar distribution is also found in regional profiles (not shown). The cause of the relatively smooth altitude distribution of emissions in the AERO2k inventory is not known. As noted by Lee et al. (2010), it is difficult to identify the causes of differences amongst inventories, although we expect AEDT to be more reliable as it is based on much more extensive movement data.

\section{Direct deposition of emissions into the strato- sphere}

Previous studies suggest that anything between $18 \%$ and $44 \%$ of total aviation emissions enter the stratosphere directly (Gettelman and Baughcum (1999)). For the North Atlantic Flight Corridor (NAFC) the estimates lie between $33 \%$ (Hoinka et al., 1993) and 62-67\% (Forster et al., 2003). There are a number of possible reasons for these differences. They each use different emission and meteorological data sets for different years. They also use different tropopause 
definitions, which have been shown to influence the amount of emissions calculated to enter into the stratosphere, and consequently their radiative impact (Gettelman (1998), Forster et al. (2003)). The lack of an accepted definition of the boundaries of the NAFC further complicates the comparison.

In this section we present a case study of the sensitivity of emissions into the stratosphere for the NAFC. The NAFC is defined here as the region bounded by $0^{\circ} \mathrm{W}, 65^{\circ} \mathrm{W}, 40^{\circ} \mathrm{N}$, and $65^{\circ} \mathrm{N}$ to encompass both transatlantic flight paths, and the typical latitudes of the extratropical jet. About $20 \%$ of global aviation emissions enter the atmosphere in this region. A blended tropopause is used, combining a dynamic tropopause (the height of the $\mathrm{PV}=2 \mathrm{PVU}$ surface) in the extratropics and a thermal tropopause in the tropics, using the algorithm described by Wilcox et al. (2012).

\subsection{Sensitivity to emissions inventory}

Figure 2(a) shows the percentage of column total emissions in the NAFC entering the stratosphere directly for February 2006 meteorology (chosen to correspond to the year of the AEDT inventory). The percentages are calculated using tropopause position calculated every 6 hours for February 2006, and monthly total emissions from the three inventories, so that all the time-variation seen in the plot is due to changes in tropopause height. On average $61 \%$ of AEDT and QUANTIFY emissions enter the stratosphere directly, compared to $54 \%$ of AERO2k emissions. This is due to the higher cruise altitude (AEDT), and higher proportion of time spent at cruise altitude (QUANTIFY). However, when 6 hourly AEDT emissions are used, in excess of $80 \%$ of column total emissions can enter the stratosphere directly in a given 6 hour period (Figure 2(b)).

\subsection{Seasonal variation in deposition}

Figure 3 shows the monthly-mean variation in the percentage of emissions deposited into the NAFC and global stratosphere for 2006, using the 6 hourly dynamic tropopause. The NAFC and global percentages peak in March at $64 \%$ and $31 \%$ respectively. Minima occur in June for the NAFC (38\%) and August globally (16\%). Figure 3 also shows the NAFC case using fixed February AEDT emissions. This is almost identical to the monthly varying AEDT case, emphasising that the seasonal variation is primarily driven by changing tropopause height, rather than seasonal changes in emission height in the inventory.

\subsection{Interannual variation in deposition}

Figure 4 shows the daily and interannual variation in the percentage of emissions deposited into the NAFC stratosphere directly for December to March (DJFM) for 6 different years using monthly-mean AEDT emissions. The choice of winters was motivated by the variations in the North Atlantic Oscillation (NAO), which is the primary mode of meteorological variability in the NAFC (e.g. Marshall et al. (2001)) (note that we neglect any dependence of the flight routing on the 

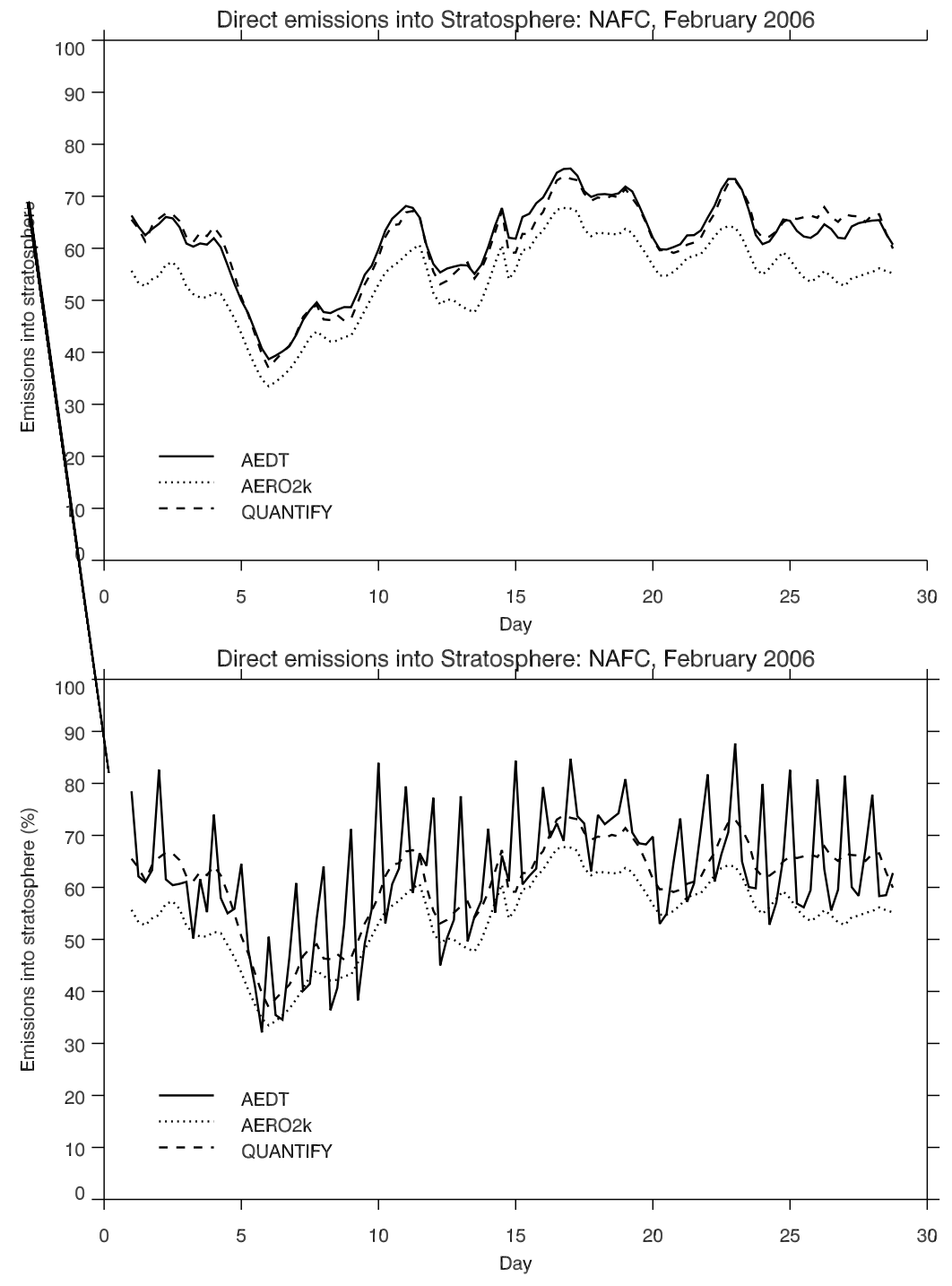

Figure 2: (a): The percentage of emissions entering the stratosphere directly for the NAFC with February 2006 meteorology, calculated using a 6 hourly dynamic tropopause and monthly-total AEDT, AERO2k, and QUANTIFY emissions. (b): As for panel (a), but using 6 hourly AEDT emissions. 


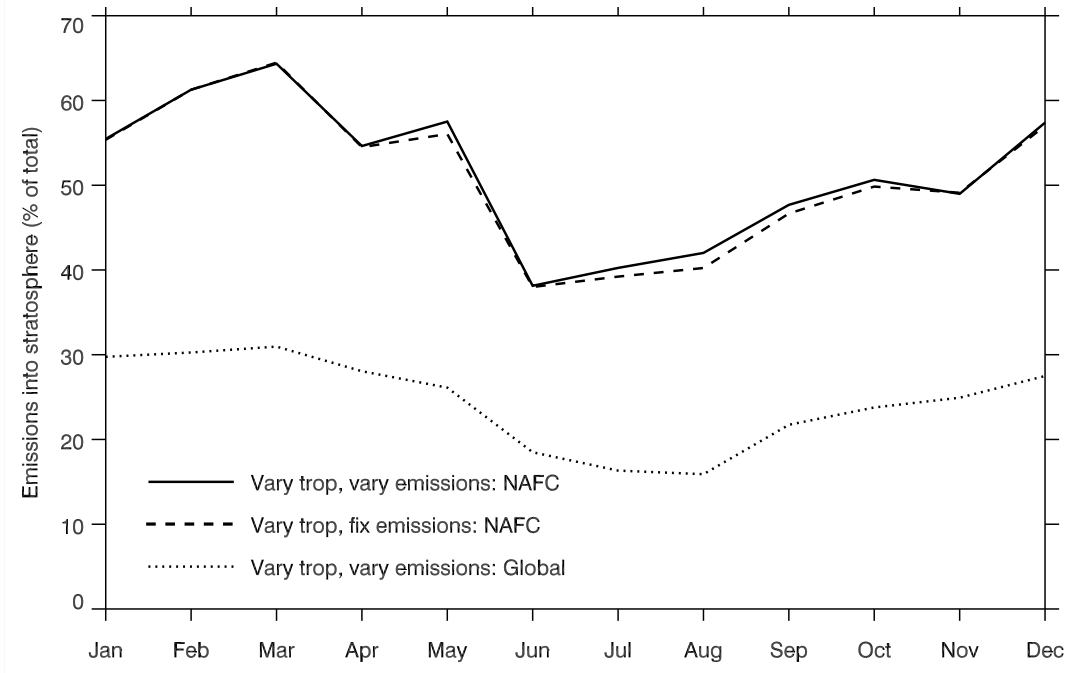

Figure 3: Monthly-mean emissions into the stratosphere as a percentage of the total in 2006. The solid line shows the NAFC values calculated using 6-hourly emissions and a 6-hourly tropopause. The dashed line shows the same, but using February emissions in all months. The dotted line shows the global values calculated using 6-hourly emissions and a 6-hourly tropopause. Emissions are from AEDT, and the dynamic tropopause is used. 
NAO). Emissions into the stratosphere in winters with a strongly positive or negative NAO index are shown in the upper and lower panel of Figure 4 respectively. The range between different years is typically $20 \%$, although occasional outliers (such as January 2006, see Figure 4(a)) are clear. There is no significant correlation between the NAO index and stratospheric emission deposition. Although the NAO influences the gradient of the tropopause across the NAFC, it does not necessarily influence the average tropopause height. The monthlymean percentage of emissions emitted directly into the NAFC stratosphere was found, as expected, to be correlated with the monthly-mean tropopause height, with $\mathrm{r}^{2}=0.88$.

\section{The trajectory model}

Fully Lagrangian trajectories have been calculated using the Methven et al. (2003) trajectory model. The model uses a $4^{t h}$ order Runge-Kutta method, with a 1 hour time step. Methven (1997) demonstrated that this time step is sufficiently small compared to the 6 hours between wind records that the integration errors in the model will be negligible compared to time truncation errors in the advecting wind field.

Trajectories are integrated on a sphere in spherical co-ordinates, using the shallow-atmosphere approximation. Horizontal wind components are taken directly from ERA-Interim wind data. Vertical wind is found from mass conservation via the continuity equation. The value of a given field is found at the position of each trajectory particle by interpolating the gridded data. Bilinear interpolation is used in the horizontal. In the vertical, Lagrange interpolation is used to capture the large gradients at the tropopause (Methven, 1997).

Water vapour is treated as a passive tracer. The only modelled removal process for emissions into the stratosphere is transport across the tropopause. Once the trajectory particles enter the troposphere it is assumed that they quickly lose their stratospheric properties through mixing, and that their associated humidity is negligible compared to the natural background. Particles are labelled as having lost their stratospheric properties after spending 24 consecutive hours below the tropopause. This criterion takes account of the typical length of time that particles spend on temporary excursions into the troposphere, and also represents a good approximation to typical mixing timescales (e.g. Shapiro (1980)). We do not explicitly model removal processes for trajectories beyond passive transport across the tropopause, the formation of ice, for example, and this is a source of uncertainty in our estimates. The calculated accumulation of water vapour is insensitive to the choice of longer removal timescales, but quite sensitive to the choice of shorter timescales that approximate the inclusion of additional removal processes. A $48 \mathrm{hr}$ removal criterion increases the accumulated mass by up to $5 \%$, instant removal decreases the accumulated mass by $20 \%$, compared to the values for a $24 \mathrm{hr}$ criterion.

As an example of transport calculated from trajectories, 50-day trajectories have been released on a regular $2^{\circ} \times 2^{\circ} \times 5 \mathrm{hPa} \times 1$ day grid in the NAFC for 


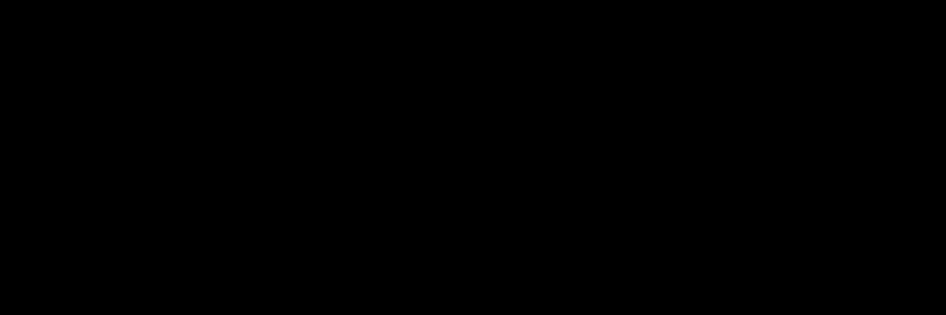

$-1988 / 8$

$-$

Figure 4: The percentage of emissions directly into the NAFC stratosphere using monthly-mean AEDT emissions and a 6 hourly tropopause for DJFM for selected years, where Day 1 is 1 December and so on. Winters with a strongly positive NAO index are shown in panel (a), and those with a strongly negative $\mathrm{NAO}$ index are shown in panel (b). 
each day in January 2004. Figure 5 shows a comparison between the number of particles remaining in the stratosphere for sets of particles released far above the extratropical tropopause at the typical cruise pressure of $225 \mathrm{hPa}(\sim 11 \mathrm{~km})$ (Figure 5a), and close to the tropopause at $300 \mathrm{hPa}(\sim 9.2 \mathrm{~km})$ (Figure 5b). The number of particles remaining in the stratosphere decreases quasi-exponentially with time for particles released at $300 \mathrm{hPa}$. However, for particles released at $225 \mathrm{hPa}$ the decrease is more linear in time.

When particles are released far above the tropopause, their rate of descent is determined by diabatic heating as they have to cross isentropic surfaces. When they are released closer to the tropopause they can be removed from the stratosphere along isentropic surfaces, or via mixing events like tropopause folding. The removal of particles is then more of a quasi-random process, resulting in an exponential decrease in numbers.

Schoeberl et al. (1998) also found that the decrease in particle numbers is not always exponential. However, unlike the results presented here, they only identified deviations from exponential decay at altitudes above the cruise altitudes of most subsonic aircraft.

\section{Accumulation of emissions in the stratosphere}

2-day long trajectories were released on a $1^{\circ} \times 1^{\circ} \times 152 \mathrm{~m} \times 6 \mathrm{hr}$ grid, covering the Northern Hemisphere. Trajectories were initialised on pressure levels corresponding to the AEDT pressure-height levels, which are based on the assumption of the International Civil Aviation Organisation (ICAO) standard atmosphere. Releases were made every $152 \mathrm{~m}$ between $466 \mathrm{hPa}$ and $151 \mathrm{hPa}$. $151 \mathrm{hPa}$ corresponds to a pressure-altitude of $13.6 \mathrm{~km}$. $466 \mathrm{hPa}$ corresponds to the altitude of the climatological minimum tropopause in December to March $(6.1 \mathrm{~km})$, when most of the trajectory analyses are performed and the minimum climatological tropopause occurs.

Once calculated, the 2-day trajectories were passed into an accumulation routine, which assigned a mass of water vapour from AEDT to each trajectory, passed mass from finishing trajectories to new 2-day long trajectories, removed any tropospheric mass using the dynamic tropopause definition and the 24 hour removal criterion, and found the accumulated mass at each point. This process is then repeated, using a succession of 2-day trajectories for the time period of interest.

The calculation of trajectories is very computationally expensive. Southern Hemisphere emissions, which represent $5 \%$ of the global total and are not expected to result in significant stratospheric accumulation, are neglected in order to allow higher resolution calculations to be performed in the Northern Hemisphere. The accumulation routine is not mass conserving as trajectories can be lost across the boundaries. In an idealised test, with one unit of mass released at each point on the release grid, $2.5 \%$ of trajectories crossed the Equator. However, when actual emissions and the tropopause removal criterion were used, no mass was lost in this way. Trajectories were generally passed into the 

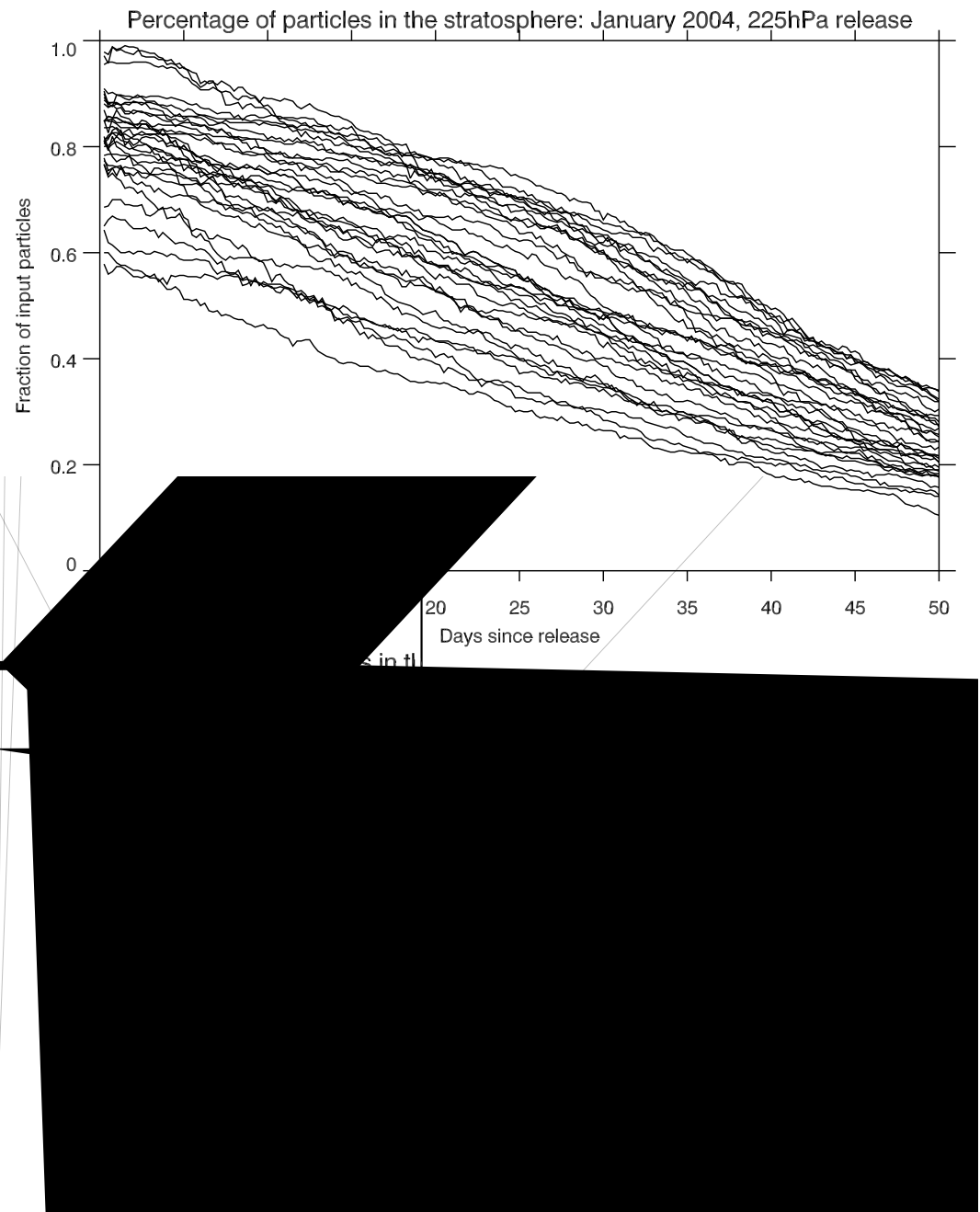

Figure 5: The fraction of input particles remaining in the stratosphere with time after their release at (a): $225 \mathrm{hPa}$ and (b): $300 \mathrm{hPa}$ in the NAFC in January 2004, calculated from ERA-Interim trajectories. Each individual line represents a release at $0 \mathrm{Z}$ on each day of the month. 


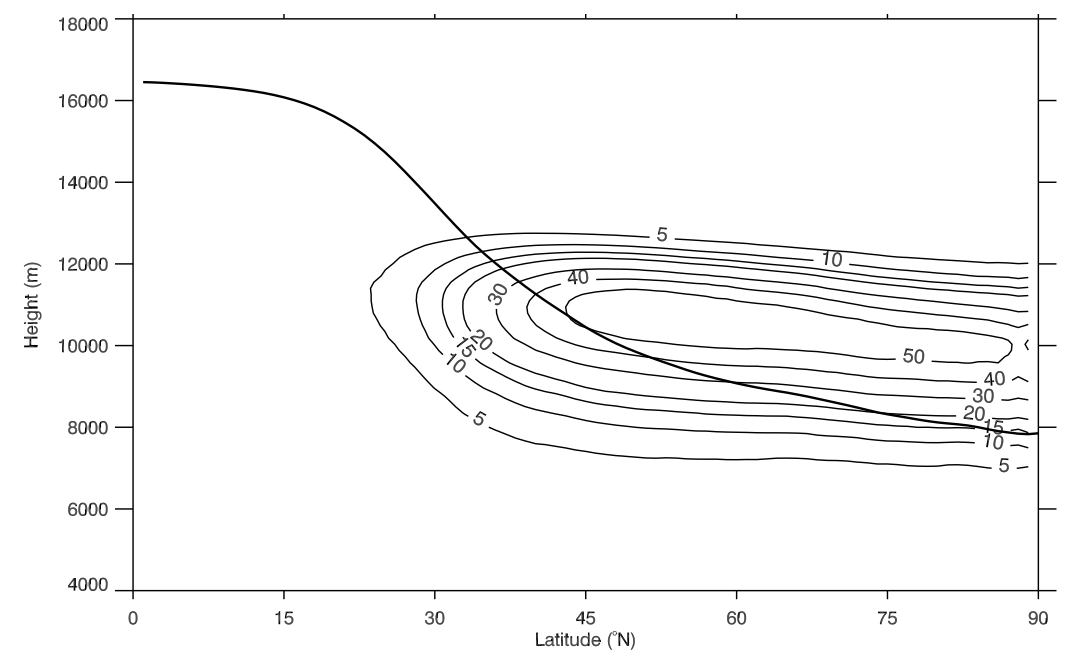

Figure 6: Annual-mean zonal-mean perturbation of water vapour (ppbv) from AEDT 2006 emissions (contours), and the 2006 annual-mean zonal-mean ERAInterim tropopause (heavy line).

troposphere, and hence the mass was lost by tropospheric mixing. $9.2 \%$ of trajectories in the same idealised test were lost above the upper boundary. Only $3.2 \%$ of actual input mass is lost via this route, as only a small mass of water vapour is input into the stratosphere near the upper boundary. It was found that this mass loss could not be notably reduced by the inclusion of a further 10 levels at lower pressures.

The accumulated mass due to stratospheric emissions was calculated for 2006, using 6 hourly AEDT emissions. Figure 6 shows the annual-mean zonalmean perturbation in the Northern Hemisphere, and the annual-mean zonalmean tropopause. The perturbation extends from $\sim 25^{\circ} \mathrm{N}$ to the pole, with some extension below the tropopause, which results from the variation of tropopause height with longitude and the use of the 24 hour removal criterion. The altitude of the maximum perturbation is close to that of maximum emission (see Figure 1), near $11 \mathrm{~km}$. The maximum zonal-mean annual-mean perturbation is 64 ppbv. The annual mean accumulation of mass in the stratosphere is $4.4 \mathrm{Tg}$.

The structure and magnitude of the zonal-mean accumulated emissions are comparable with the work of Fichter (2009) who found a maximum zonal-mean perturbation of 69 ppbv; Gauss et al. (2003) found 109 ppbv for the NASA 2015 inventory, which equates to a 63 ppbv perturbation if scaled by the ratio of the total AEDT emissions to the total NASA 2015 emissions; and Morris et al. (2003) found 100 ppbv for the NASA 2015 inventory, which scales to a 58 ppbv AEDT 2006 equivalent. The results shown in Figure 6 also compare well with the 55 ppbv maximum perturbation at $10 \mathrm{~km}$ found by Danilin et al. 


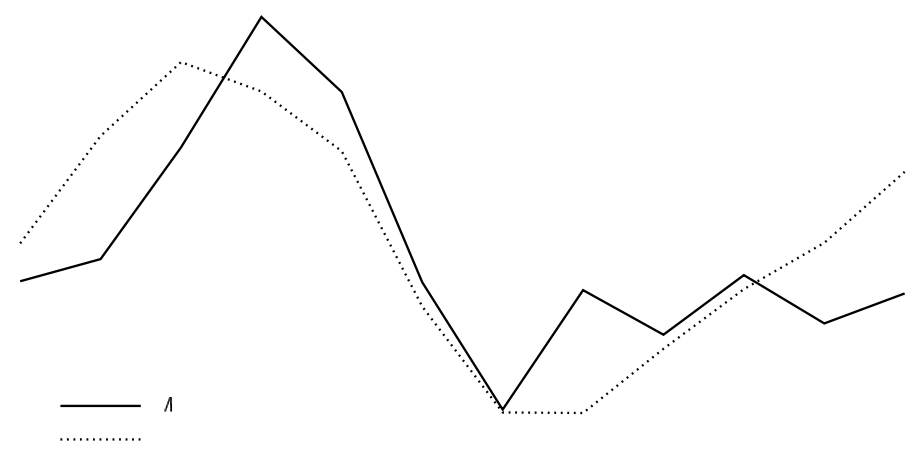

Figure 7: Maximum zonal-mean monthly-mean water vapour perturbation (ppbv) calculated using AEDT 2006 emissions and ERA-Interim trajectories (solid line). The monthly-mean mass ( $\mathrm{Tg}$ ) of water vapour accumulated in the stratosphere is also shown (dotted line).

(1998). However, the magnitudes of the perturbations are much smaller than those presented by Hoinka et al. (1993) (380 ppbv). Fortuin et al. (1995) chose residence times of 0.5 and 2.5 years, based on the then available literature, deriving changes in mixing ratio of 76 and 380 ppbv respectively, using a simple 1-dimensional approach. Their lower value is much nearer to the value derived here.

There is a strong seasonal cycle in both the peak zonal-mean monthly-mean perturbation, and the total mass of emissions accumulated in the stratosphere (see Figure 7). The largest peak zonal-mean perturbation of 85 ppbv occurs in April, and the smallest occurs in July (50 ppbv). This cycle mirrors the cycle in the total accumulated mass in the stratosphere, except that the maximum mass in the stratosphere $(6.1 \mathrm{Tg})$ occurs in March. The cycle is broadly consistent with the annual cycle of the emissions into the stratosphere in the NAFC shown in Figure 3.

The cycle in the peak zonal-mean perturbation is comparable to the cycle identified by Fichter (2009) who found a maximum zonal-mean perturbation of $107 \mathrm{ppbv}$ in May and $45 \mathrm{ppbv}$ in September using the TRADEOFF inventory and EC39A model. However, the cycle found here has a smaller amplitude, and is shifted by two months. When the TRADEOFF inventory is used with the Methven (1997) trajectory model, the perturbations are 30\% smaller than those found by Fichter (2009), probably reflecting the different treatment of transport and removal processes. 


\begin{tabular}{|l|cc|cc|cc|}
\cline { 2 - 7 } \multicolumn{1}{c|}{} & \multicolumn{2}{c|}{ Jan } & \multicolumn{2}{c|}{ Feb } & \multicolumn{2}{c|}{ Mar } \\
& ppbv & Tg & ppbv & Tg & ppbv & Tg \\
\hline DJFM 2003/2004 & 60 & 5.5 & 64 & 5.7 & 70 & 5.4 \\
DJFM 1994/1995 & 60 & 5.7 & 63 & 6.0 & 70 & 6.1 \\
DJFM 1995/1996 & 66 & 5.5 & 65 & 6.0 & 75 & 6.0 \\
DJFM 1997/1998 & 66 & 5.6 & 66 & 5.7 & 71 & 5.7 \\
\hline
\end{tabular}

Table 2: Maximum zonal-mean monthly-mean perturbation (ppbv) and the monthly-mean mass accumulated in the stratosphere $(\mathrm{Tg})$, for the four winters considered.

\subsection{Sensitivity to interannual variability in meteorology}

Stratospheric water vapour perturbations due to aircraft emissions have been calculated for DJFM 2003/2004, DJFM 1994/1995, DJFM 1995/1996, and DJFM 1997/1998. These years were chosen as they represent different phases of the NAO (the DJFM time series of this index is available at www.cgd.ucar.edu/cas/jhurrel/indices.html). DJFM $2003 / 2004$ is a winter with only a very slightly negative NAO index (-0.07), and will be used as a base case for comparison with the other winters. DJFM 1994/1995 has a strongly positive NAO index (3.96), and DJFM 1995/1996 has a strongly negative NAO index (-3.78). A large El Niño occurred in DJFM 1997/1998. The NAO index had a value of 0.72 in that period. Typically, it takes 2 to 3 weeks for the mass of the accumulated water vapour in the stratosphere to reach equilibrium. Hence, December is regarded as a spin-up month.

There is a degree of inter-annual variability in the magnitude and structure of the water vapour perturbations. The primary drivers of this variability appear to be the height of the zonal-mean tropopause and the sign of the zonal-mean vertical velocities. However, there is no obvious link between the phase of the $\mathrm{NAO}$ and the structure of the zonal-mean perturbation, which is consistent with the lack of variation in the deposition of emissions into the stratosphere related to different phases of the NAO (Figure 4). The strongly negative and positive $\mathrm{NAO}$ case studies actually result in perturbations that are more similar to each other than they are to the base case.

Table 2 shows the peak zonal-mean monthly-mean stratospheric water vapour perturbations for each of the months considered, and the accumulated mass in the stratosphere. The perturbations have a spread of $10 \%$ of the maximum perturbation in January, and 5\% in February and March. The accumulated mass has a spread of $3 \%$ of the maximum accumulation in January, $6 \%$ in February, and $13 \%$ in March.

\subsection{Sensitivity to emissions inventory}

Calculations were performed for DJFM 2003/2004 meteorology using the AERO2k and QUANTIFY inventories, in addition to the AEDT inventory. As shown in 
Figure 1, the three inventories have different vertical emission distributions, which influences the mass of the emissions that enter the stratosphere directly (Figure 2). Consistent with this, there is also a large impact on the accumulated mass of water vapour in the stratosphere, with AEDT almost double the mass $(5.5 \mathrm{Tg})$ is accumulated compared with AERO2k (2.8 Tg) using January 2004 meteorology for both. QUANTIFY gives similar results $(5.1 \mathrm{Tg})$ to AEDT (Table 3). The distribution of the accumulated emissions is similar for all three inventories.

\section{Radiative forcing due to aviation water vapour emissions}

The radiative forcing due to aviation water vapour emissions has been calculated using the Edwards and Slingo (1996) radiative transfer model (ES). ES is a broadband code based on the two-stream approximation to the radiative transfer equations. For shortwave calculations the 'Practical Improved Flux Method' from Zdunkowski et al. (1980) was used. For longwave calculations the 1985 version of the Practical Improved Flux Method was used, with Elsasser's value of 1.66 for the diffusivity factor.

ES was used with 9 bands in the longwave region, and 6 in the shortwave. The spectral characteristics follow those used in the 60 level HadGEM2 model (Collins et al., 2008). Scattering is considered, and clouds are represented using the maximum random overlap approximation. The Gaussian integration method, with six intervals, is used to integrate the shortwave irradiance over daylight hours for the $15^{\text {th }}$ day of each month, which is used as a monthly-mean.

Two radiative forcings are calculated (see e.g. Forster et al. (2007)). The first is the instantaneous forcing, in which the water vapour is perturbed but all other parameters are kept fixed. The second, which we will focus on as it is considered to be more relevant (Forster et al., 2007), is the adjusted radiative forcing, in which stratospheric temperatures are adjusted to a new equilibrium in response to the water vapour change. Since the stratosphere cools in response to the addition of water vapour, and thus acts to decrease the infrared emission into the troposphere, the forcing is decreased relative to the instantaneous case (e.g. Forster and Shine (2002)). The temperature adjustment is calculated using the fixed-dynamical heating approximation (Fels et al., 1980).

There has been some debate about the usefulness of broadband radiation models for quantifying the radiative effects of stratospheric water vapour perturbations (e.g. Forster et al. (2001); Oinas et al. (2001); Maycock and Shine (2012)). Myhre et al. (2009) compared a series of broadband models, to more accurate line-by-line and narrowband models, for a uniform perturbation of 3 to $3.7 \mathrm{ppmv}$ in the stratosphere, and for perturbations due to subsonic and supersonic aircraft emissions. They found that the difference in net instantaneous radiative forcing between models was in excess of a factor of two, and that the results from ES in particular deviated from the results from other models 
(their Figure 1). However, the adjusted radiative forcing from ES compared well with the results from a narrowband model (their Figure 3) although there was a significant dependence on the exact configuration of the ES code used. As shown by Maycock and Shine (2012) the ES code gives a 15-30\% (depending on stratospheric conditions) higher adjusted forcing compared to a more detailed radiation code. Although more sophisticated codes are available, the large number of calculations that were required for this work meant that a fast code was needed. As adjusted radiative forcing will primarily be considered, the ES code was used.

Zonal-mean monthly-mean climatological fields of pressure, temperature, specific humidity, ozone, cloud cover, and cloud liquid and ice water contents have been produced from gridded ERA-Interim data, and used as input to ES. Well-mixed concentrations of methane (704 ppbv), carbon dioxide (320 ppmv), nitrous oxide (260 ppbv), and oxygen (23.6\%) are also specified. ES is used with a spatial resolution of $1^{\circ}$ latitude, with 37 pressure levels up to $1 \mathrm{hPa}$, matching the vertical resolution of ERA-Interim. The radiative forcing is interpolated to the position of the ERA-Interim tropopause.

Radiative forcing calculations have been performed for the perturbations discussed in Section 5. The sensitivity of the radiative forcing due to aviation water vapour emissions to the background meteorology is investigated using January, February, and March perturbations for five winters: 1995, 1996, 1998, 2004 and 2006. In each case trajectories for the winter being investigated are used with emissions from the AEDT 2006 inventory. Radiative forcing calculations are performed using the relevant background climatology and tropopause for that season. The effect of the choice of emissions inventory on radiative forcing is also quantified. The seasonal cycle in radiative forcing, and its annual average, are presented based on perturbations calculated using ERA-Interim trajectories and the AEDT 2006 inventory.

Figure 8 shows the adjusted radiative forcing and accumulated mass in the stratosphere due to aviation water vapour emissions for the meteorology of February 1995, 1996, 1998, 2004 and 2006. February is shown, as this is the month with the largest spread at any given latitude (up to a third of the maximum forcing). The forcings are comparable equatorward of $\sim 45^{\circ} \mathrm{N}$, but they diverge poleward of this latitude. In 1995 and 1996 the distribution of forcings is very similar, despite the contrasting NAO indices in these years. There is not necessarily correspondence between the total accumulated aviation water vapour in the stratosphere and the adjusted radiative forcing as the radiative forcing is dependent both on the mass of water vapour, and its position relative to the tropopause.

The largest range of global-mean radiative forcing values across the four winters considered occurs in March, with a spread of $23 \%$ of the maximum radiative forcing. The smallest range of values is found in January $(8 \%$ of the maximum January-mean forcing). In January and February the maximum global-mean monthly-mean forcing occurs in 1996. In March it occurs in 1995.

Radiative forcing was also calculated for January, February and March using 2004 meteorology and the AEDT, AERO2k and QUANTIFY inventories. The 

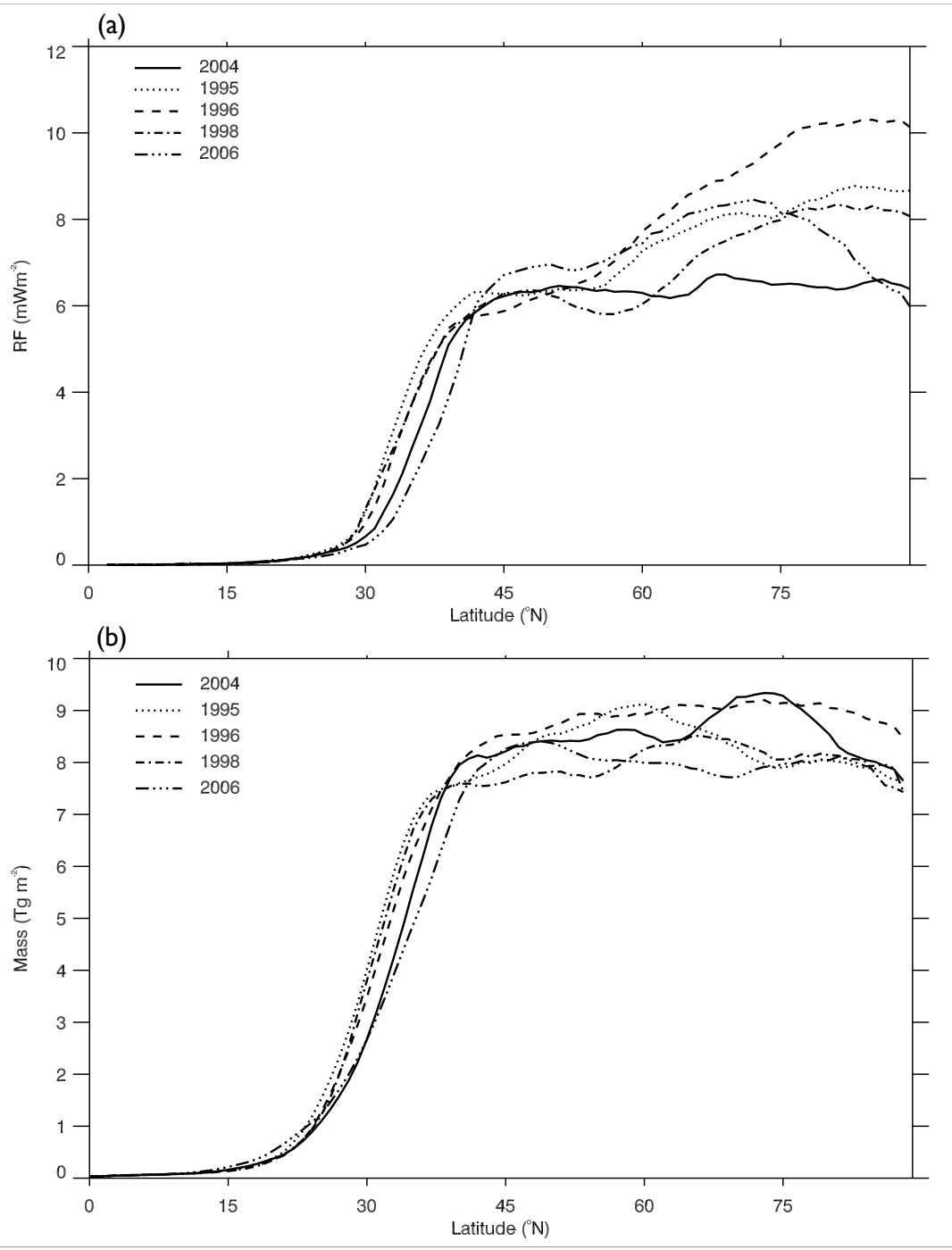

Figure 8: (a): Zonal-mean monthly-mean adjusted radiative forcing and (b): zonal-total column-total monthly-mean accumulated mass for January 2004, 1995, 1996, and 1998 and 2006 meteorology and AEDT 2006 emissions. 


\begin{tabular}{|c|c|c|}
\hline Inventory & Accumulated mass (Tg) & $\begin{array}{c}\text { Adjusted radiative forcing } \\
\left(\mathrm{mW} \mathrm{m}^{-2}\right)\end{array}$ \\
\hline AEDT & 5.5 & 1.38 \\
AERO2k & 2.8 & 0.68 \\
QUANTIFY & 5.1 & 1.21 \\
AERO2k (norm.) & 3.4 & 0.81 \\
QUANTIFY (norm.) & 4.5 & 1.07 \\
\hline
\end{tabular}

Table 3: Monthly-mean accumulated mass and monthly-mean global-mean adjusted radiative forcing for January 2004 meteorology using AEDT, AERO2k, and QUANTIFY emissions. 'norm' indicates where results have been normalised to the total mass of AEDT emissions.

inventories are for different years, and have different monthly total emissions. Table 3 shows the monthly mean values for January for each inventory. The forcings are also presented for the AERO2k and QUANTIFY inventories normalised using the ratio of monthly total emissions to those from AEDT 2006. This removes any differences resulting from different total emissions, leaving only those due to different emissions distributions. However, even when the forcings are normalised with respect to AEDT emissions in this way, there is still a large spread in the radiative forcing (see Table 3), with radiative forcing due to AEDT emissions around 60\% larger compared to that due to AERO2k. Even though QUANTIFY provides a greater mass of input emissions compared to AEDT (Table 1), a smaller radiative forcing results from this (Table 3), as the emissions are located at lower altitudes (Figure 1).

Figure 9 shows the monthly-mean, global-mean adjusted radiative forcing due to AEDT water vapour emissions. The annual cycle is in phase with the annual cycle in total mass of water vapour accumulation in the stratosphere (Figure 7), with a maximum of $1.34 \mathrm{~mW} \mathrm{~m}^{-2}$ in March, and a minimum of $0.36 \mathrm{~mW} \mathrm{~m}^{-2}$ in August. The annual-mean global-mean adjusted forcing at the dynamic tropopause is $0.86 \mathrm{~mW} \mathrm{~m}^{-2}$ for 2006. It can be seen from Figure 8 that a degree of interannual variability should be expected in this value. For comparison, the annual-mean global-mean instantaneous forcing is $1.61 \mathrm{~mW}$ $\mathrm{m}^{-2}$.

The uncertainties associated with interannual variability, the choice of inventory and meteorological data sets, the choice of tropopause definition, and the uncertainties associated with the radiative calculation are assumed to be independent. The uncertainty from the choice of inventory is $\pm 30 \%$ based on the difference between radiative forcing from AEDT and AERO2k emissions, although it is believed that AEDT is more reliable, so this might overestimate the true uncertainty. Interannual variability in the meteorology introduces an uncertainty of $\pm 25 \%$, based on the range of radiative forcing estimates for different winters. This represents an upper limit as the uncertainty from interannual variability is based only on winter calculations here, and interannual variability 


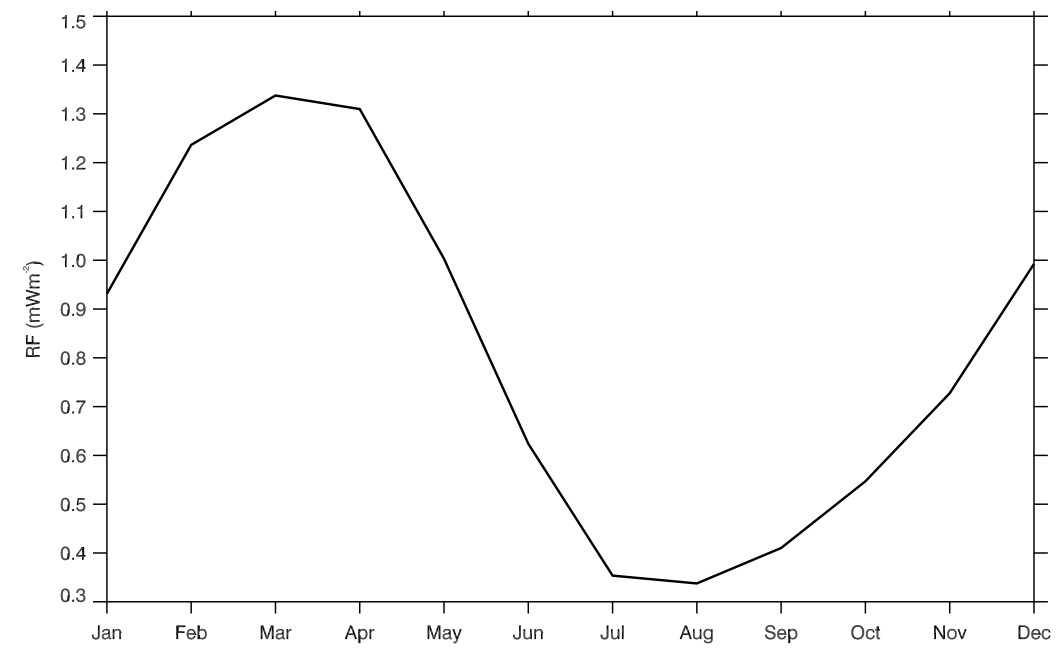

Figure 9: Global-mean monthly-mean adjusted radiative forcing for 2006, calculated using AEDT 2006 emissions.

is expected to be smaller in the summer months. Following Myhre et al. (2009), a further $\pm 25 \%$ uncertainty comes from the radiative calculations. An uncertainty of $\pm 10 \%$ arises from the choice of the meteorological data set, based on the comparison of results from ERA-Operational and ERA-Interim trajectories and tropopause height. The choice of tropopause definition itself resulted in an uncertainty of $\pm 30 \%$ in stratospheric deposition in the NAFC. It is expected that it will result in a smaller uncertainty in global-mean radiative forcing. However, this has not been tested, so it has been assumed that the choice of tropopause definition also results in a $\pm 30 \%$ uncertainty in the radiative forcing, as we wish to determine the largest estimate of the uncertainty range. Symmetric uncertainties have been presented here in order to give the largest range of estimates. However, this is unlikely to be the most accurate representation, particularly in the case of the emissions inventories where AEDT is believed to be more representative of the distribution of actual emissions. Similarly, ERAInterim is believed to give more realistic results compared to ERA-Operational. Additionally, assuming that radiative forcing scales with mass accumulated in the stratosphere, there is also up to a $5 \%$ underestimate in global-mean radiative forcing that results from neglecting Southern Hemisphere emissions. As discussed in Section 4, assumptions about the loss of water vapour from the stratosphere also lead to an uncertainty, so that the stratospheric accumulation could be overestimated by $20 \%$ if all water vapour in cross-tropopause trajectories was lost immediately. Because we have tried to quantify the upper limit of the uncertainties here, we interpret the overall uncertainty range as representing two standard deviations from the best estimate. 
The square root of the sum of the squares of these uncertainties gives an overall uncertainty of $+56 \% /-60 \%$. Hence, the annual-mean global-mean adjusted radiative forcing for 2006 is estimated to be 0.86 [0.34 to 1.34$] \mathrm{mW} \mathrm{m}^{-2}$.

The temperature change, calculated using the fixed-dynamical heating approximation that is used for the stratospheric adjustment, due to aviation water vapour emissions is small. The largest change is located just above the tropopause near $60^{\circ} \mathrm{N}$, and reaches $-50 \mathrm{mK}$ in February.

\section{Comparison with previous work}

The best estimate of the adjusted radiative forcing due to aviation water vapour emissions presented here is small compared to those presented in the assessments of IPCC (1999) (1.5 $\mathrm{mW} \mathrm{m}^{-2}$ for 1992), Sausen et al. (2005) $\left(2.0 \mathrm{~mW} \mathrm{~m}^{-2}\right.$ for 2000), and Lee et al. (2009) (2.8 $\mathrm{mW} \mathrm{m}^{-2}$ for 2005). The Sausen et al. (2005) and Lee et al. $(2009,2010)$ values are essentially scaled versions of the $1.5 \mathrm{~mW}$ $\mathrm{m}^{-2}$ presented in IPCC (1999), even though the IPCC value does not seem to be based on any detailed calculations (see their Section 6.3.5).

Sausen et al. (2005) present mean values for the year 2000, found from the results of the TRADEOFF project. No emissions inventory was available for 2000 at the time. They used a 1991/92 movements base year, corrected by ICAO statistics, to give 2000 emissions.

Sausen et al. (2005) scaled their $\mathrm{CO}_{2}, \mathrm{O}_{3}$ and $\mathrm{CH}_{4}$ results by 1.15 , following IPCC (1999), to account for the underestimate inherent in using an inventory, which arise from the assumptions of optimal routing. In IPCC (1999), this scaling is also applied to the water vapour radiative forcing. However, Sausen et al. (2005) do not discuss water vapour in any detail, and do not appear to apply this scaling factor. They find a radiative forcing due to water vapour of $2.0 \mathrm{~mW} \mathrm{~m}^{-2}$ for 2000 emissions, which is much larger than the $0.86 \mathrm{~mW} \mathrm{~m}^{-2}$ for 2006 emissions found here.

Lee et al. (2009) also only briefly discuss water vapour forcing. They scale Sausen et al. (2005)'s year 2000 result to IEA fuel sales for 2005, to give an estimate of radiative forcing for the year 2005. Lee et al.'s $(2009,2010)$ best estimate was $2.8 \mathrm{~mW} \mathrm{~m}^{-2}$. This is three times larger than the value presented here, and double the upper end of our uncertainty range. The upper limit of Lee et al.'s $(2009,2010)$ likelihood range was $20.3 \mathrm{~mW} \mathrm{~m}^{-2}$. This is more than 20 times larger than the best estimate presented here, and 15 times the upper end of the uncertainty range. It is deemed very unlikely that water vapour emissions from aircraft could cause such a large radiative forcing. The Lee et al. (2009) upper limit of the forcing does not originate from a detailed assessment of individual sources of uncertainty. Rather, it originates from the assumption that the uncertainties in the water vapour forcing follow a log-normal distribution and from a choice of a somewhat arbitrary near-zero lower limit to this forcing; this was influenced by an assertion that the IPCC (1999) had stated that the lower limit of the forcing was zero, although IPCC (1999) did not perform any detailed assessment of the water vapour forcing or its uncertainty. 
Despite being small relative to the best estimates presented in the above assessments of the climate impact of aviation, our estimate of the radiative forcing due to aviation water vapour emissions is comparable to the estimates of Fichter (2009), Gauss et al. (2003), and Ponater et al. (2006). Fichter (2009) found an adjusted radiative forcing of $1.0 \mathrm{~mW} \mathrm{~m}^{-2}$ for TRADEOFF 2000 emissions, which she scaled up to $1.5 \mathrm{~mW} \mathrm{~m}^{-2}$ to account for uncertainties in the radiative calculation. Gauss et al. (2003) found an instantaneous radiative forcing of $2.6 \mathrm{~mW} \mathrm{~m}^{-2}$ using the NASA 2015 inventory. When scaled to the AEDT 2006 emissions, this has an equivalent of $1.51 \mathrm{~mW} \mathrm{~m}^{-2}$, which compares well to the instantaneous global-mean forcing of $1.61 \mathrm{~mW} \mathrm{~m}^{-2}$ found here. Ponater et al. (2006), also using the NASA 2015 inventory, found an adjusted radiative forcing of $2.8 \mathrm{~mW} \mathrm{~m}^{-2}$ for a fleet of cryoplanes, which has an AEDT 2006 equivalent of $0.64 \mathrm{~mW} \mathrm{~m}^{-2}$.

The better agreement between these focused studies and the work presented here further suggests that the best estimate presented by Lee et al. $(2009,2010)$ is too large by at least a factor of two.

\section{Radiative forcing as a function of emission height}

Radiative forcing has been calculated for $500 \mathrm{~m}$ deep layers of emissions in order to illustrate how emissions at different heights contribute to the total radiative forcing. It also provides a simple means of estimating the impact of changing the altitude of emissions on radiative forcing, assuming an unchanged geographical distribution. Grewe and Stenke (2008) and Fichter (2009) have previously presented, on a latitude-height grid, a similar diagnostic. The values presented here are convolved with the geographical distribution of present-day aviation emissions and hence may be more easily applied to examining the impact of changes in the cruise altitude of the present-day fleet.

The global-mean radiative forcing per $\mathrm{Tg}$ of input water vapour emissions per month, assuming the geographical distribution in the AEDT 2006 emissions, is shown in Figure 10 for January 2004 meteorology. Radiative forcing increases almost linearly with height of emission.

The sum of the radiative forcings due to the separate layers of input emissions is $1.47 \mathrm{~mW} \mathrm{~m}^{-2}$ for AEDT emissions and January 2004 meteorology. This is within $10 \%$ of the radiative forcing estimate from the actual perturbation (1.38 $\mathrm{mW} \mathrm{m} \mathrm{m}^{-2}$ ), suggesting that for water vapour emissions specific radiative forcings could be combined with input emissions to give a good first-order estimate of the resultant radiative forcing, provided the geographical distribution of emissions is similar to that in AEDT.

If all emissions that currently enter the atmosphere above $9 \mathrm{~km}$ are assumed to enter the stratosphere at an altitude of $12 \mathrm{~km}$, with the same geographical distribution as AEDT 2006 emissions, the resultant radiative forcing can be estimated from Figure 10. A monthly emission above $9 \mathrm{~km}$ of $13 \mathrm{Tg}$ (Table 1) 


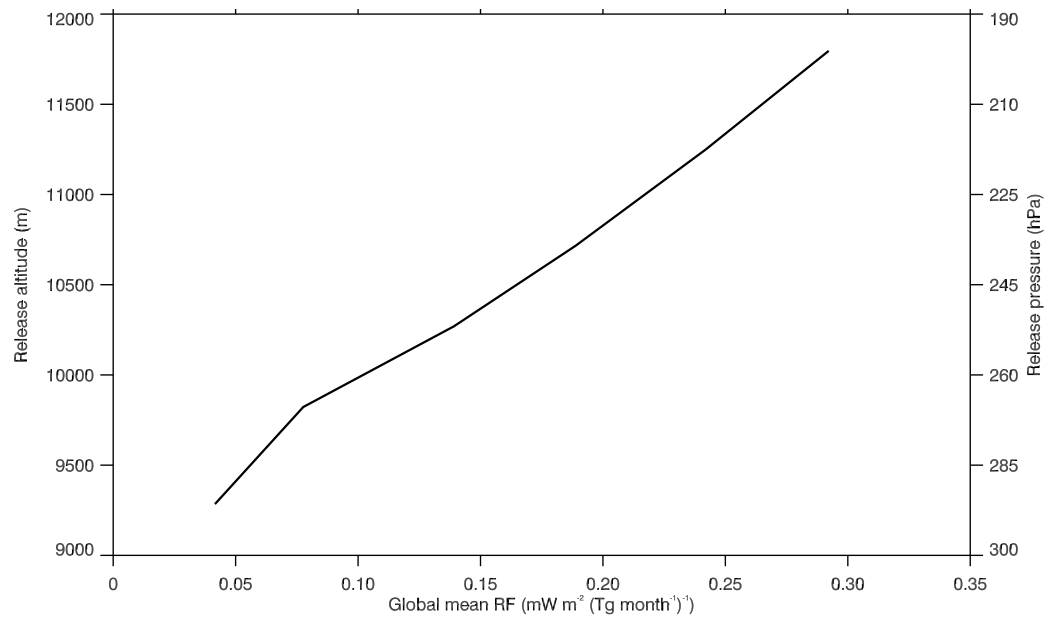

Figure 10: The global-mean adjusted radiative forcing per unit emissions as a function of release altitude for January 2004 meteorology.

will have a radiative forcing of $0.31 \mathrm{~mW} \mathrm{~m}^{-2}\left(\mathrm{Tg} \mathrm{month}^{-1}\right)^{-1}$, giving a monthlymean global-mean adjusted radiative forcing of $4.0 \mathrm{~mW} \mathrm{~m}^{-2}$. This value, which could be considered an extreme case, is still a factor of 5 smaller than the upper bound of the Lee et al. $(2009,2010)$ estimate.

\section{Conclusions}

Large differences have been identified in the distribution of emissions within the AEDT, AERO2k and QUANTIFY inventories. The largest differences are found at cruise altitudes. This results in marked differences in stratospheric deposition and accumulation, and represents the largest source of difference in the radiative forcing calculations performed here.

Analysis of trajectories initialised in the lower stratosphere demonstrated that the assumption of an e-folding time for stratospheric emissions is not always appropriate, particularly for emissions far above the tropopause, where a linear model is more appropriate.

Stratospheric deposition of emissions and accumulation are sensitive to the position of the tropopause, which results in a seasonal cycle in the accumulated emissions in the stratosphere. For 2006, peak zonal-mean monthly-mean accumulated water vapour emissions had a maximum of $85 \mathrm{ppbv}$ in April and a minimum of $50 \mathrm{ppbv}$ in July. The annual average perturbation had a maximum zonal-mean of 64 ppbv.

An annual-mean global-mean adjusted radiative forcing of 0.86 [0.34 to 1.34] $\mathrm{mW} \mathrm{m} \mathrm{m}^{-2}$ was found for 2006, using AEDT 2006 emissions. This is around one 
third of the best estimate presented in the recent assessments by Lee et al. $(2009,2010)$. The top of our uncertainty range, which we interpret to represent two standard deviations, is 15 times smaller than the upper bound of their $90 \%$ confidence interval, suggesting that a radiative forcing due to aviation water vapour emissions of this order is not plausible.

\section{Acknowledgements}

This work was funded by the U.S. Federal Aviation Administration (FAA) under contract award DTRT57-07-P-80162. Any opinions, findings, and conclusions or recommendations expressed in this material are those of the authors and do not necessarily reflect the views of the research sponsor.

The authors would like to acknowledge the use of the UK National Grid Service in carrying out this work, and the use of ERA data made available by the British Atmospheric Data Centre (BADC) and National Centre for Atmospheric Science (NCAS)-Climate. Thanks also to Christine Frömming (née Fichter) for providing raw data for comparison, John Methven for the use of the trajectory code, Amanda Maycock for guidance on the use of the Edwards and Slingo radiation code, and two anonymous reviewers for their helpful suggestions.

\section{References}

Collins, W.J., Bellouin, N., Doutriaux-Boucher, M., Gedney, N., Hinton, T., Jones, C.D., Liddicoat, S., Martin, G., O'Connor, F., Rae, J., C., S., Totterdell, I., Woodward, S., Reichler, T., Kim, J., 2008. Evaluation of the HadGEM2 model. Technical Note 74. Hadley Centre.

Danilin, M.Y., Fahey, D.W., Schumann, U., Prather, M.J., Penner, J.E., Ko, M.K.W., Weisenstein, D.K., Jackmann, C.H., Pitari, G., Köhler, I., Sausen, R., Weaver, C.J., Douglass, A.R., Conell, P.S., Kinnison, D.E., Dentener, F.J., Fleming, E.L., Berntsen, T.K., Isaksen, I.S.A., Haywood, J.M., Kárcher, B., 1998. Aviation fuel tracer simulation: Model intercomparison and implications. Geophysical Research Letters 25, 3947-3950.

Dee, D.P., Uppala, S.M., Simmons, A.J., Berrisford, P., Poli, P., Kobayashi, S., Andrae, U., Balmaseda, M.A., Balsamo, G., Bauer, P., Bechtold, P., Beljaars, A.C.M., van de Berg, L., Bidlot, J., Bormann, N., Delsol, C., Dragani, R., Fuentes, M., Geer, A.J., Haimberger, L., Healy, S.B., Hersbach, H., Hólm, E.V., Isaksen, L., Kållberg, P., Köhler, M., Matricardi, M., McNally, A.P., Monge-Sanz, B.M., Morcrette, J.J., Park, B.K., Peubey, C., de Rosnay, P., Tavolato, C., Thépaut, J.N., Vitart, F., 2011. The era-interim reanalysis: configuration and performance of the data assimilation system. Quarterly Journal of the Royal Meteorological Society 137, 553-597.

Edwards, J.M., Slingo, A., 1996. Studies with a flexible new radiation code. 1: 
Choosing a configuration for a large-scale model. Quarterly Journal of the Royal Meteorological Society 122, 689-719.

Eyers, C., Norman, P., Middel, J., Plohr, M., Michot, S., Atkinson, K., Christou, R., 2004. AERO2k global aviation emissions inventories for 2002 and 2025. Technical Report. QinetiQ Ltd. http://www.cate.mmu.ac.uk/aero2k.asp.

Fels, S., Mahlman, J.D., Schwarzkopf, M.D., Sinclair, P.W., 1980. Stratospheric sensitivity to pertubations in ozone and carbon dioxide: Radiative and dynamical response. Journal of Atmospheric Science 37, 2265-2297.

Fichter, C., 2009. Climate Impact of Air Traffic Emissions in Dependency of the Emission Location and Altitude. DLR-FB-2009-22. Deutsches Zentrum für Luft- und Raumfahrt.

Forster, C., Stohl, A., James, P., Thouret, V., 2003. The residence times of aircraft emissions in the stratosphere using a mean emission inventory and emissions along actual flight tracks. Journal of Geophysical Research 108, 8524 .

Forster, P., Ramaswamy, V., Artaxo, P., Berntsen, T., Betts, R., Fahey, D., Haywood, J., Lean, J., Lowe, D., Myhre, G., Nganga, J., Prinn, R., Raga, G., Schulz, M., Dorland, R.V., 2007. Changes in atmospheric constituents and in radiative forcing. In: Climate Change 2007: The Physical Science Basis. Contribution of Working Group I to the Fourth Assessment Report of the Intergovernmental Panel on Climate Change. Cambridge University Press, Cambridge, United Kingdom and New York, NY, USA.

Forster, P.M.D., Ponater, M., Zhong, W.Y., 2001. Testing broadband radiation schemes for their ability to calculate the radiative forcing and temperature response to stratospheric water vapour and ozone changes. Met Zeitschrift $10,387-393$.

Forster, P.M.D., Shine, K.P., 2002. Assessing the climate impact of trends in stratospheric water vapor. Geophysical Research Letters 29.

Fortuin, J.P.F., van Dorland, R., Wauben, W.M.F., Kelder, H., 1995. Greenhouse effects of aircraft emissions as calculated by a radiative transfer model. Annales Geophysicae 13, 413-418.

Gauss, M., Isaksen, I.S.A., Wong, S., Wang, W.C., 2003. The impact of $\mathrm{H}_{2} \mathrm{O}$ emissions from kerosene aircraft and cryoplanes in the atmosphere. Journal of Geophysical Research 108.

Gettelman, A., 1998. The evolution of aircraft emissions in the stratosphere. Geophysical Research Letters 25, 2129-2132.

Gettelman, A., Baughcum, S., 1999. Direct deposition of subsonic emissions into the stratosphere. Journal of Geophysical Research 104, 8317-8327. 
Grewe, V., Stenke, A., 2008. Airclim: an efficient tool for climate evaluation of aircraft technology. Atmospheric Chemistry and Physics 8, 4621-4639.

Hoinka, K.P., Reinhardt, M.E., Metz, W., 1993. North atlantic air traffic within the lower stratosphere: Cruising times and corresponding emissions. Journal of Geophysical Research 98, 23113-23131.

IPCC, 1999. Aviation and the global atmosphere. A special report of IPCC Working Groups I and III in collaboration with the scientific assessment panel to the Montreal Protocol on substances that deplete the ozone layer, Cambridge University Press.

Kentarchos, A.S., Roelofs, G.J., Lelieveld, J., 2000. Simulation of extratropical synoptic-scale stratosphere-troposphere exchange using a coupled chemistry GCM: Sensitivity to horizontal resolution. Journal of Atmospheric Science $57,2824-2838$.

Kim, B., Fleming, G., Balasubramanian, S., Malwitz, A., Lee, J., Ruggiero, J., Waitz, I., Klima, K., Stouffer, V., Long, D., Kostiuk, P., Locke, M.and Holsclaw, C., Morales, A., McQueen, E., Gillette, W., 2005. SAGE, System for assessing Aviation's Global Emissions, Version 1.5. Technical Report FAA-EE-2005-01. FAA.

Land, C., Feichter, J., Sausen, R., 2002. Impact of vertical resolution on the transport of passive tracers in the ECHAM4 model. Tellus 54B, 344-360.

Lee, D.S., Fahey, D.W., Forster, P.M., Newtone, P.J., Wit, R.C.N., Lim, L.L., Owen, B., Sausen, R., 2009. Aviation and global climate change in the 21st century. Atmospheric Environment 43, 3520-3537.

Lee, D.S., Pitari, G., Grewe, V., Gierens, K., Penner, J.E., Petzold, A., Prather, M.J., Schumann, U., Bai, A., Berntsen, T., Iachetti, D., Lim, L.L., Sausen, R., 2010. Transport impacts on atmosphere and climate: Aviation. Atmospheric Environment 44, 4678-4734.

Liu, Y.S., Fueglistaler, S., Haynes, P.H., 2010. Advection-condensation paradigm for stratospheric water vapor. Journal of Geophysical Research 115, D24307.

Malwitz, A., Kim, B., Fleming, G., Lee, J., Balasubramanian, S., Waitz, I., Klima, K., Locke, M., Holsclaw, C., Morales, A., McQueen, E., Gillette, W., 2005. SAGE, System for assessing Aviation's Global Emissions, Version 1.5: Validation Assessment, Model Assumptions and Uncertainties. Technical Report FAA-EE-2005-03. FAA.

Marshall, J., Kushnir, Y., Battisti, D., Change, P., Czaja, A., Dickson, R., Hurrell, J., McCartney, M., Saravanan, R., Visbeck, M., 2001. North Atlantic climate variability: Phenomena, impacts and mechanisms. International Journal of Climatology 21, 1863-1898. 
Maycock, A.C., Shine, K.P., 2012. Stratospheric water vapor and climate: Sensitivity to the representation in radiation codes. J. Geophys. Res. 117, D13102.

Methven, J., 1997. Offline trajectories: Calculation and accuracy. Tech. Report 44. University of Reading. U.K. Univ. Global Atmos. Modelling Programme, Dept. of Meteorol., Univ. of Reading, Reading, U.K.

Methven, J., Arnold, S., O'Connor, F., Barjat, H., Dewey, K., Kent, J., Brough, N., 2003. Estimating photochemically produced ozone throughout a domain using flight data and a lagrangian model. Journal of Geophysical Research 108,4271 .

Morris, G.A., Rosenfield, J.E., Schoeberl, M.R., Jackman, C.H., 2003. Potential impact of subsonic and supersonic aircraft exhaust on water vapor in the lower stratosphere assessed via a trajectory model. Journal of Geophysical Research $108,4103$.

Myhre, G., Kvalevaag, M., Rädel, G., Cook, J., Shine, K.P., Clark, H., Karcher, F., Markowicz, K., Kardas, A., Wolkenberg, P., Balkanski, Y., Ponater, M., Forster, P., Rap, A., de Leon, R.R., 2009. Intercomparison of radiative forcing calculations of stratospheric water vapour and contrails. Meteorologische Zeitschrift 18, 585-596.

Oinas, V., Lacis, A.A., Rind, D., Shindell, D.T., Hansen, J.E., 2001. Radiative cooling by stratospheric water vapor: Big differences in GCM results. Geophysical Research Letters 28, 2791-2794.

Owen, B., Lee, D.S., Lim, L., 2010. Flying into the future: Aviation emissions scenarios to 2050. Environmental Science and Technology 44, 2255-2260.

Ponater, M., Pechtl, S., Sausen, R., Schumann, U., Hüttig, G., 2006. Potential of the cryoplane technology to reduce aircraft climate impact: A state-of-theart assessment. Atmospheric Environment 40, 6928-6944.

Sausen, R., Isaksen, I., Grewe, W., Hauglustaine, D., Lee, D.S., Myhre, G., Köhler, M.O., Pitari, G., Schumann, U., Stordal, F., Zerefos, C., 2005. Aviation radiative forcing in 2000: An update on IPCC (1999). Meteorologische Zeitschrift 14, 555-561.

Schoeberl, M.R., Jackman, C.H., Rosenfield, J.E., 1998. A lagrangian estimate of aircraft effluent lifetime. Journal of Geophysical Research 103, 1081710825 .

Shapiro, M.A., 1980. Turbulent mixing within tropopause folds as a mechanism for the exchange of chemical constituents between the troposphere and stratosphere. Journal of Atmospheric Science 37, 994-1004.

Wilcox, L.J., Hoskins, B.J., Shine, K.P., 2012. A global blended tropopause based on ERA data. Part 1: Climatology. Quarterly Journal of the Royal Meteorological Society 138, 561-575. 
${ }_{714}$ Zdunkowski, W.G., Welch, R.M., Korb, G., 1980. An investigation of the structure of typical two-steam methods for the calculation of solar fluxes and heating rates in clouds. Beitraege zur Physik der Atmosphaere 53, 147-166. 